\title{
11 de septiembre, "Economía del Terror" y Cumbre de Qatar
}

- Francisco Javier Ibisate

\section{1. ¿Economía del terror?}

El término ha sido acuñado en la reunión del Grupo de los 20 (G-20), que tuvo lugar en la ciudad canadiense de Ottawa, el 17 de noviembre de 2001. "Los ministros de economía de los veinte países pactan medidas para asfixiar la «economía del terror». Economía del terror serían las fuentes de financiamiento que sostienen la cadena de actos terroristas previos y posteriores a los ataques del 11 de septiembre en Nueva York y Washington. El G-20 se ha comprometido a "poner en práctica, con carácter de urgencia, las medidas de la ONU para acabar con el financiamiento del terrorismo, y cada uno congelará activos de los terroristas y sus asociados, cuyas identidades y cantidades embargadas se notificarán públicamente". El G-20 se compromete a ayudar a aquellos países que, por sí mismos, no están capacitados técnica y financieramente a enfrentar el desafío terrorista: "Bloquearemos el acceso de los terroristas a nuestro sistema financiero".

No deja de llamar la atención la relevancia que tiene la presente convocatoria. El G-20 fue creado y convocado en Berlín, el mes de diciembre de 1999, como un grupo consultivo, a raíz de la crisis financiera suscitada entre 1997 y 1998, que había sacudido las principales bolsas de valores y golpeado frontalmente a países del bloque sudasiático, así como a Rusia y Brasil... La agenda consultiva de Berlín se centraba en la forma de control de los capitales de libre movimiento, el papel del FMI en la crisis, la responsabilidad de los inversores priva- 
dos imprudentes, sin que se dieran respuestas concretas a estos puntos de agenda. Dos años más tarde, en Ottawa la consulta se traduce en un compromiso, donde al Grupo de los Siete (G-7) se agregan otros trece países, entre los cuales se merece destacar a Rusia y China, integrados en la lucha antiterrorista, y Arabia Saudí, de cuyo interior parece que emana un denso flujo de financiamiento de grupos terroristas de inspiración islámica. El pánico que el difuso terrorismo ha generado en las grandes potencias occidentales, se ha traducido en la gestación de más amplias alianzas antiterroristas. Quedan dos interrogantes: "Expertos en relaciones internacionales consideran que el compromiso del G-20 tiene un flanco muy débil en el frente de los países islámicos. Otro es la ausencia de una fecha límite para cumplir este objetivo". ("Alianza contra las finanzas del terrorismo", El País, 18-11-01)

En Ottawa los ministros de economía y los gobernadores de bancos centrales despliegan el área de los afectados por los actos terroristas: "los países pobres serán los más perjudicados por el actual enfriamiento de la economía, agravada por los sucesos del 11 de septiembre... La pobreza en muchos países en desarrollo probablemente se agravará, porque estos acontecimientos han agudizado el enfriamiento previo de la economía global, que ya había llevado a menores exportaciones y caída de precios de las materias primas". A estos efectos se agregará "un mayor número de refugiados, menores inversiones privadas por la aversión al riesgo y menores rentas por turismo debido al temor a viajar".

En Ottawa se presenta otra cara de la economía del terror, que bien puede llamarse economía del miedo o de la inseguridad, que ya existía antes del 11 de septiembre y que - siendo sinceros - puede alentar al mismo terrorismo. A partir del 11 de septiembre, "el mundo es diferente, más integrado y tiene que haber más unión entre países pobres y desarrollados, porque la alienación, la pobreza, la violencia, la ira son una amenaza para la paz y la prosperidad en todo el mundo", afirmó un delegado del Banco Mundial.

Parecería que la nueva economía del terror está ayudando a descubrir la antigua economía de la incertidumbre. Esto significa que las economías desarrolladas se sienten atemorizadas desde el doble flanco del terror y de la incertidumbre. J. Wolfensohn concluye que "el Banco Mundial asume que debe ayudar más a los países pobres". Puesto que la pobreza es una amenaza para la paz y se hacen necesarias más ayudas, urgen programas reales para la lucha contra la pobreza. No se trata de repartir "cheques en blanco", sino donaciones efectivas en la reducción de la pobreza. Wolfensohn dice que "más ministros que nunca han hablado sobre el incremento de las ayudas al desarrollo, aunque no hay consenso". ("El Banco Mundial asume que debe ayudar más a los países pobres", El País, 19-11-01) Como veremos enseguida, no hubo mucho consenso acerca de la ayuda en la conferencia de la Organización Mundial del Comercio (OMC), concluida tres días antes de la reunión de Ottawa. 


\section{Navidades con rebajas}

En vísperas de la reunión de Ottawa varias instituciones ponen cifras a la recesión mundial. "El FMI rebaja la previsión de crecimiento mundial por segunda vez en dos meses". Si el 27 de septiembre se proyectaba una tasa de crecimiento mundial de $2,6 \%$, dos meses después se vaticina un $2,4 \%$. Las tres principales economías tenderán a deprimirse aún más en 2002. Estados Unidos crecerá $1,1 \%$ en 2001 y sólo un $0,7 \%$ en 2002. La Unión Europea (UE) logrará un 1,7\% en 2001 y $1,4 \%$ en 2002 . En Japón se pronostican tasas de crecimiento negativas de $0,9 \%$ en 2001 y $1,3 \%$ en 2002 . El director del FMI, Horst Köhler, estima que la situación es "claramente difícil" y que luego del 11 de septiembre se convierte en adivinatorio el ejercicio de hacer prospectiva económica. "Tenemos que reconocer que hacemos frente a un extraordinario grado de incertidumbre como consecuencia de los ataques del 11 de septiembre. No hay precedentes para una situación como ésta, por lo que hacer previsiones basándose en experiencias previas es poco menos que hacer adivinanzas". "A una economía mundial, ya en claro proceso de enfriamiento, los ataques del 11 de septiembre le han venido a dar la puntilla", viene a decir el informe. ("El FMI rebaja la previsión de crecimiento mundial por segunda vez en dos meses", El País, 16-11-01)

$\mathrm{La}$ OCDE, cuyos treinta países concentran la mayor parte de la riqueza mundial, afirma que los ataques del 11 de septiembre "han propinado un choque severo a la economía mundial". La OCDE pronostica que el crecimiento de los Estados Unidos será de 1,1\% este año, y una contracción del $0,1 \%$ en el primer semestre de 2002, seguida de un sólido avance de $3,8 \%$ en la segunda mitad, para producir un crecimiento total de $0,7 \%$ en 2002 . En la zona del euro se espera un crecimiento de $1,6 \%$ este año, seguido de un $1,4 \%$ y un $3,0 \%$ para 2002 y 2003 . Japón se contraerá $0,7 \%$ en 2001 y $1,0 \%$ en 2002 , con un pequeño crecimiento de $0,8 \%$ en 2003 . ("OCDE contempla recesión mundial", LPG, 21$11-01 ;$ p.47)

Dentro del sesgo adivinatorio de estas proyecciones hay un consenso en que la recesión será prolongada y difícil. Un crecimiento de $2,4 \%$ de la economía mundial significa una recesión real, porque no compensa el crecimiento de la población. También la CEPAL avanza algunas proyecciones para América Latina. "La comisión estima que este año América Latina crecerá entre 0,5 y 1,0 por ciento, Para 2002 se prevé un crecimiento entre 1,5 y 2,0 por ciento". La inversión extranjera directa caerá de 57 mil millones de dólares en 2000 a 50 mil millones este año, debido a la desaceleración de la economía mundial. Se verán afectados los precios de las materias primas, sobre todo petróleo y metales, y no tanto los alimentos. El turismo en la zona del Caribe se ha reducido un $50 \%$ y el efecto mayor es la incertidumbre, porque los efectos del 11 de septiembre están por verse. Si la economía de los Estados Unidos comienza a recuperarse en el segundo semestre de 2002, esto pudiera generar un crecimiento del $1,5 \%$ o $2,0 \%$ 
en la región. ("Inversión extranjera en América Latina caerá \$ 7 mil millones". LPG, 21-11-01; p. 57)

El 16 de octubre, la Directora Regional de la CEPAL en México, Rebeca Gryspan, vaticinaba momentos difíciles para América Latina en 2001 y 2002, y que el PIB puede bajar un punto. Para El Salvador y Costa Rica los efectos serían sensibles en la maquila y el turismo. "Es importante no soltar los sectores sociales y guardar el capital humano (educación, salud, jóvenes y niñez), de lo contrario el deterioro sería irreversible". Segundo, "las economías centroamericanas deberían poner los ojos en la región"; ya que la desaceleración viene de fuera no debemos relegar la cooperación interna entre países". ("Crisis impactará la región". LPG, 16-10-01)

Sin detallar tasas de crecimiento mundiales o regionales, Jeffrey Sachs, reconocido economista de Harvard y asesor económico de varios países, nos envía un lacónico mensaje: "Recesión durará mientras dure la guerra. Fuga de capitales e inversiones". Sus ideas claves son: "Ni siquiera Estados Unidos va a salir de la recesión hasta que termine la guerra, que ha enviado un claro mensaje de que el mundo no es un lugar seguro para las inversiones. Ningún país va a escapar del impacto de la guerra. Todos los mercados emergentes están siendo golpeados duramente por los enfrentamientos". Para Sachs hay dos factores que retroalimentan la recesión mundial: la guerra, que no sabemos cuánto puede durar, y el mundo, que no es un lugar seguro para las inversiones.

Refiriéndose a nuestro continente, Sachs pronostica que este próximo período "va a ser muy duro para América Latina, que experimentará un alejamiento de las inversiones internacionales y una caída del flujo de capitales directos, lo que podría ocasionar debilitamientos políticos... Toda la región va a estar bajo el impacto directo de la recesión de los Estados Unidos y deberá pasar por una trayectoria muy difícil. Las economías no van a reactivarse hasta que termine la guerra y eso no se sabe cuándo será, dado el sombrío ambiente financiero". Repitió que Estados Unidos está claramente en recesión, lo que agravará el problema de la desaceleración económica que se está experimentando en el mundo entero, que no es un lugar seguro para inversores y acreedores. Si sumamos los augurios de J. Sachs a la prospectiva económica de Horst Köhler, resulta un ejercicio adivinatorio el pronóstico de un 3\% de nuestra economía en 2002, superando incluso las tasas de la CEPAL para América Latina. Cada año el BCR debe reconocer que puso la vara demasiado alta.

Queda pendiente un interrogante mayor. En Ottawa se ha dicho que "el mundo es diferente, más integrado y tiene que haber más unión entre países pobres y desarrollados, porque la alienación, la pobreza, la violencia, la ira son una amenaza para la paz y la prosperidad en todo el mundo". El interrogante es si el mundo actual da muestra de una real integración de pobres y desarrollados. La muestra más cercana sería la cumbre de la Organización Mundial del Comer- 
cio (OMC) en Doha, Qatar, que se clausuró tres días antes de la reunión de Otawa. No nos vamos a encontrar con argumentos fehacientes de la supuesta integración.

\section{Terrorismo no, pobreza tampoco}

La cumbre de la OMC se prolonga de un día, 9-14 de noviembre, coincidiendo con la $56^{\mathrm{a}}$ Asamblea General de las Naciones Unidas en Nueva York. La batalla contra el terrorismo es el punto mayor en Nueva York; el debate sobre la pobreza se lleva a cabo en Qatar. Una de las personas que lanza el puente entre terrorismo y pobreza es el Secretario General de las Naciones Unidas, Kofi Annan, frente al unilateralismo de George W. Bush que se planta en una lado del puente. El diario Le Monde dice que Bush se presenta ante la ONU fortalecido por la primera victoria militar, y El País agrega que "Bush urge a la ONU a sumarse a la batalla contra el terrorismo. Toda una generación tiene hoy el deber de acabar para siempre con una amenaza planetaria". Las afirmaciones se acompañan de amenazas. Quien no se oponga a los terroristas que amenazan a "toda la civilización", y no dudarían en utilizar armas nucleares "para convertir su odio en un holocausto, pagará las consecuencias". "La única alternativa a la victoria, dijo, es un mundo de pesadilla en el que cualquier ciudad es escenario potencial de una matanza...Después de la tragedia hay un tiempo para la misericordia y las condolencias. Y mi país agradece mucho ambas cosas. Las ceremonias y las vigilias no serán olvidadas, pero el momento de las muestras de simpatía ya ha pasado. Ha llegado el momento de la acción". ("Bush urge a la ONU a sumarse a la batalla contra el terrorismo". El País, 11-11-01)

Le tocará a Kofi Annan ampliar el abanico de otras modalidades de terrorismo. El primero de noviembre y desde el Centro Internacional del Trabajo, Ginebra, solicitó el fin rápido de los bombardeos. "Cuanto más rápido terminen las operaciones militares, tanto mejor para llevar la ayuda humanitaria. Es indispensable poder trabajar en un ambiente más tranquilo", lamentando los obstáculos al transporte de las ayudas que constituyen los ataques aéreos y el pillaje de los centros de acopio humanitario que hacen los talibanes. Kofi Annan advirtió que "cuanto más se prolongue el conflicto mayor es la probabilidad de que se generen más tensiones, cuando lo importante es mantener un frente unido contra el terrorismo". Las Naciones Unidas deben esforzarse por combatir la pobreza, el SIDA y otros conflictos, incluidos los cambios climáticos. Todos estos problemas pueden alimentar el terrorismo". Por ello solicitó que la próxima conferencia de la OMC "contribuya a ratificar nuevas negociaciones comerciales favorables a los países en desarrollo". ("Kofi Annan souhaite la fin rapide des bombardements". Le Monde, 04-11-01)

En la sede de la ONU y frente al unilateralismo de Bush, Kofi Annan presenta otras prioridades a la comunidad internacional. "Estamos tentados de con- 
centrar todas nuestras energías en la lucha contra el terrorismo, pero esto sería conceder la victoria a los terroristas, porque los problemas a que nos habíamos enfrentado el 10 de septiembre (cumbre de Nueva York de 2000) no han cambiado, sino que se hacen más urgentes. Para evitar un enfrentamiento mútuamente destructivo entre las mismas civilizaciones, es necesario dar una esperanza real a millones de personas cercadas por la pobreza, los conflictos y las enfermedades". Al mismo tiempo, Kofi Annan exhortó a los Estados miembros a adelantar su trabajo para ratificar un acuerdo global sobre la definición de terrorismo. Tarea nada fácil, por cierto, siendo una realidad tan pluriforme, donde la campaña militar en Afganistán es calificada por muchos como terrorismo de Estado. ("M. Annan apelle á vaincre le terrorisme sans négliger la lutte contre la pauvreté de millions de persones". Le Monde, 10-11-01) Este discurso inaugural de K. Annan sirvió de puente entre la Asamblea General de Nueva York y la cumbre de la OMC en Qatar.

\section{La sombra de Seattle}

La cumbre de la OMC en Qatar se abre a la sombra de dos fantasmas: Osama Bin Laden, inspirador de los ataques terroristas que han agravado una economía debilitada, y el fracaso de la OMC en Seattle, acaecido en diciembre de 1999. Si el primer fantasma generó la economía del terror, el segundo fantasma puso en evidencia las relaciones asimétricas del comercio internacional, la impagable deuda externa, dando vigor al movimiento antiglobalización. Si en Qatar no se llegaba a un acuerdo final la economía mundial entraría en mayores angustias y tensiones, en nada propicias a la unificación antiterrorista. El hecho de que se prolongara de un día esta cumbre, para poder llegar a un acuerdo final, es prueba de las fuertes tensiones entre Norte y Sur. Los países pobres y emergentes no estaban dispuestos a ceder, ni los desarrollados muy anuentes a conceder.

En Seattle cuarenta mil manifestantes pacíficos se unen a los reclamos de los países pobres. Las economías desarrolladas subvencionan ilegalmente sus exportaciones y cierran sus fronteras con aranceles y barreras sanitarias a las exportaciones del Sur. Los delegados de los países pobres se negaron a firmar un documento final sobre el que no habían sido consultados. "No sabemos qué decisiones se van a tomar y una vez más se nos pedirá suscribir un texto que ni tendremos tiempo de leer". El fracaso de Seattle ha sido interpretado como una victoria de los países pobres.

Joseph Stiglitz, jefe de economistas del Banco Mundial, había dicho que el libre comercio en poco o en nada había beneficiado a los países pobres y que la teoría del libre comercio era un "fraude intelectual". Luego de esta afirmación, y por presiones bien conocidas, J. Stiglitz fue relegado del BM. Para dolor de sus detractores, J. Stiglitz ha sido galardonado con el Premio Nobel de Economía 
2001, por su “teoría de las asimetrías". En reciente viaje a Quito, que tuvo lugar en octubre de 2001, Stiglitz dijo que la globalización debería suponer para todos los países una franca apertura de mercados para lograr un mayor crecimiento. Las naciones podrían beneficiarse del derrumbamiento de las barreras del comercio. La manera como ha sido empujado el 'fundamentalismo del mercado' ha causado tensiones fuertes. La forma en que ha sido concebida la globalización "no ha sido transparente", ni justa para los países pobres por las desventajas comparativas con las naciones desarrolladas. La liberación comercial internacional ha sido elaborada por las naciones desarrolladas sin tomar en cuenta las opiniones de otros países o sectores económicos que están inmiscuidos en el proceso. La "gobernabilidad esta fuera de foco" cuando no concierta ni transparenta los mecanismos de integración comercial o financiera entre todos los integrantes". ("Premio Nobel sugiere cambiar globalización", LPG, 27-10-01; p. 43)

El día 9 de noviembre, fecha en que se inicia la cumbre de la OMC, el editorial de Le Monde resume las tensiones de Seattle y de Qatar: el sistema comercial mundial provoca excesivas desigualdades y hay que corregirlo y reformarlo si se quiere mejorar la credibilidad de la OMC. "El fracaso de Seattle se debe al hundimiento de la fosa profunda entre países desarrollados y en vías de desarrollo desde hace diez años. El Norte resulta hipócrita al reclamar del Sur una apertura de sus fronteras en los nuevos sectores (telecomunicaciones, seguros, bienes farmacéuticos), al mismo tiempo que mantiene cerradas sus fronteras a los sectores de menor tecnología que el Sur puede exportar (agricultura, textiles, acero). Europa, Estados Unidos y Japón dedican mil millones diarios para sostener sus agriculturas, seis veces más que su ayuda a los países en desarrollo. Por otro lado, imponen el respeto a los derechos de propiedad intelectual en productos vitales como las medicinas, haciendo ilusorio el derecho a la salud".

Luego del fracaso de Seattle, una nueva quiebra en Qatar sería desastrosa para una economía mundial en recesión, que pudiera alimentar la tentación del proteccionismo o del nacionalismo. "Nadie ganaría con ello". Los países del Norte se han beneficiado durante cincuenta años con la apertura del comercio, pese a las dolorosas reestructuraciones impuestas. Los países del Sur se verían privados de mercados en el Norte, en un momento en que los atentados del 11 de septiembre y la inseguridad generada en las empresas y bancos occidentales amenazan con una repatriación de sus inversiones. En estas circunstancias se hace necesario proseguir el diálogo. "La creación de la OMC es una victoria del Derecho Internacional contra las solas relaciones de las fuerzas del mercado"." L'OMC et le Sud", Le Monde, 09-11-01)

Con la misma fecha, George Soros recomienda "arreglar, no destruir la OMC", por ser una institución valiosa y, de muchas maneras, la institución internacional más desarrollada. Sin embargo, la OMC es el objetivo principal de los opositores a la globalización; hay que admitir que tiene fallas. Tanto en Seattle como 
en Qatar se va a solicitar que en los acuerdos de la OMC se integren cláusulas sobre normas laborales (trabajo infantil, entre otros), medidas medioambientales y de derechos humanos. G. Soros plantea, en primer lugar, el problema general y aclara cuáles son las funciones propias de la OMC. "En efecto el problema fundamental del orden global de la actualidad es que la producción de bienes privados ha adquirido prioridad sobre el desarrollo social; es decir, el suministro de bienes públicos". La OMC no está diseñada ni autorizada para imponer normas de protección ambiental, normas laborales (OIT), derechos humanos. Estas funciones son competencia de otras instituciones internacionales o se debaten en cumbres mundiales, como el Protocolo de Kioto en Bonn. La función de la OMC es hacer cumplir las reglas del comercio internacional pactadas en las sucesivas rondas y aprobadas por unanimidad de los países miembros. George Soros se pregunta: “¿Sería concebible que China (integrada en Qatar a la OMC) aceptara la inclusión de los derechos humanos? ¿Podría ser Estados Unidos más sensible con cuestiones del medio ambiente?".

Soros sugiere que en vez de imponer requerimientos difíciles de cumplir se debe ayudar con recursos para que voluntariamente los apliquen. Por ejemplo, recursos para la educación primaria para ir eliminando el 'trabajo infantil'. También habrá que hacer cambios significativos en los reglamentos de la OMC, que ha llegado a ser muy poderosa. "En cierto sentido, la OMC es víctima de su propio éxito" y por ello debe escuchar las objeciones válidas. Un ejemplo concreto, punto de litigo en Qatar, son los derechos de propiedad intelectual, que, siendo necesarios, pueden convertirse en una limitación del comercio. “¿Qué tanta restricción está justificada?" Otro punto sería el acuerdo de Medidas de Inversión Relacionadas con el Comercio, que juegan a favor de los inversionistas y corporaciones internacionales y que dañan a las pequeñas y medianas locales. Como este tema vuelve a ser punto de litigio en Qatar, Soros recomienda revisar estas normas a fin de evitar una oposición a la OMC. "Y puesto que los mercados globales requieren de instituciones internacionales capaces de sostenerlos, la OMC resulta una institución valiosa y, sin duda de muchas maneras, la institución internacional más desarrollada. Ha tenido éxito no sólo al crear leyes internacionales, sino también al adjudicar disputas y al hacer cumplir sus decisiones". ("Arreglar, no hundir la OMC”, El País, 09-11-01)

\section{Se reunió la cumbre de Qatar}

Era necesario borrar la imagen y el fracaso de Seattle. En la reunión de Davos 2000, Tony Blair y Bill Clinton propusieron lanzar una nueva ronda de la OMC ese mismo año, aprovechando la euforia que había generado la "nueva economía" de los Estados Unidos. La nueva economía o el nuevo comienzo prometía crecimientos sostenidos de la economía mundial, propicios para la apertura comercial. Pero en los dos últimos años se clausuraron una serie de reuniones internacionales (G-7, G-8, FMI), siempre con la promesa de lanzar un nuevo 
ciclo de cumbres donde tuvieran acogida los intereses de todos los miembros, incluidos los países pobres. El conflicto de Kosovo, las crecientes manifestaciones antiglobalización y la misma elección de G.W. Bush no eran el mejor preámbulo para un multilateralismo comercial. Los atentados del 11 de septiembre y su impacto en la debilitada economía mundial hacían esperar un repliegue de las economías sobre sí mismas, en primer lugar los Estados Unidos; un nuevo proteccionismo. "Los responsables de la política plantean ahora la urgencia de un acuerdo comercial mundial”. Suprimir la cumbre de Qatar sería agravar más la recesión mundial.

"No ha habido cambios después de Seattle". En Doha se repiten las mismas quejas. Los países en desarrollo se oponen al cierre de sus productos agrícolas y textiles en los mercados del Norte y su dificultad para acceder a los medicamentos. Los países ricos quieren que se integren en las relaciones comerciales los derechos sociales (acabar con el trabajo infantil) y normas ambientales, lo que es visto como un proteccionismo disimulado. Norteamericanos y europeos se resisten a reducir las subvenciones a sus agriculturas. Joseph Stiglitz, Premio Nobel 2001, dijo al día siguiente de su nominación: "Desearía ver que el próximo ciclo sirviera a corregir los desequilibrios del pasado y dar muestras de mayor sensibilidad ante las necesidades de los países en desarrollo. Las subvenciones a la agricultura es un tema muy importante y un sector donde los países en desarrollo son perjudicados".

Para los responsables de la política económica mundial lo peor hubiera sido clausurar esta conferencia, como se había hecho con otras reuniones. La misma tragedia del 11 de septiembre ha motivado la necesidad de actuar colectivamente. "El regreso de los Estados Unidos al juego multilateral puede ser decisivo". Algo ha cambiado, cuando el regreso de los republicanos a la Casa Blanca auguraba la era de una Norteamérica conquistadora y unilateral. El auge pasado había creado doce millones de empleos y George W. Bush era un campeón del libre mercado y los Estados Unidos debían liderar el comercio internacional. Bush prometía "un mercado totalmente abierto" que permitiera a empresas y consumidores norteamericanos comprar más barato una amplia gama de productos. El objetivo de Doha es llegar a un ciclo más equilibrado y más justo, aunque en nada se han aplacado las pasadas discrepancias. ("La bataille de Doha n'est pas gagnée”, Le Monde, 10-11-01)

Luego de un centenar de reuniones desde el inicio del año los organizadores de la cumbre trataron de ser concisos y prudentes en la presentación de los documentos preparatorios, evitando la complejidad de los borradores de Seattle. En nueve páginas y cuarenta y tres párrafos se planteaban los temas iniciales sometidos a discusión. En texto aparte se agregaba la puesta en obra de los acuerdos de la Ronda de Uruguay (1987), así como los acuerdos sobre la propiedad intelectual, acceso a los medicamentos y el tema de la salud pública. Toda 
prudencia era necesaria para que en Doha se pudiera llegar a un documento final. He aquí un esquema de los temas más espinosos:

Agricultura. Le Monde habla de la tradicional manzana de la discordia. Las subvenciones agrícolas enfrentan de nuevo a la Unión Europea (UE) con los dieciocho países del Grupo de Cairns, grandes exportadores de estos productos (Canadá. Argentina, Brasil, Australia...), que reclaman la supresión de todas las ayudas a la agricultura, lo que no acepta la UE en Bruselas. El borrador no es aceptable para la UE e incluso para EE.UU.: "reducciones de todas las formas de subvenciones a la exportación, con miras a su progresiva reducción”. Los europeos, que en Seattle habían defendido el "carácter multifuncional" de la agricultura, estarían dispuestos a conceder un régimen preferencial a las exportaciones de los países en desarrollo, pidiendo que se reconozcan las contribuciones no comerciales propias de la agricultura.

Acceso a los medicamentos. Tema muy sensible. Los países en desarrollo cuestionan los derechos de las grandes empresas farmacéuticas por ser demasiado honerosos cuando se trata de las epidemias, como el SIDA, malaria, tuberculosis...Algunos países, como Estados Unidos y Suiza, se resisten a hacer mayores concesiones, argumentando que ello dañaría la investigación. El tema es delicado por estar en juego la salud de millones de personas de escasos recursos, que no podrán beneficiarse de los cuidados apropiados.

El medio ambiente. Con parecido argumento de salvaguardar la salud pública y proteger el medio ambiente, la Unión Europea aparece como el jefe de fila. Los Estados Unidos y los países en desarrollo ven ahí una forma de proteccionismo para limitar las exportaciones, como carnes tratadas con hormonas y las verduras genéticamente modificadas.

Normas sociales. En la cumbre de la OMC en Seattle Bill Clinton había solicitado la aplicación de ciertas normas laborales, porque el comercio internacional busca también el desarrollo de las personas. Esta demanda provocó la ironía de los europeos y el rechazo de los países pobres, porque el Gobierno de los EE.UU. no había ratificado las normas de la Organización Internacional del Trabajo (OIT) y porque sería un proteccionismo disimulado contra exportaciones del tercer mundo. Como indicara G. Soros, este debate debe llevar a un diálogo entre la OMC y la OIT, que es "el lugar apropiado" para discutir la dimensión social de la globalización.

Inversiones y competencia. La confrontación viene de lejos, dadas las disimetrías técnico-financieras entre los miembros de la OMC. En teoría habría que establecer normas claras que protegieran las inversiones y el respeto a la competencia, pero los países en desarrollo se quejan de ser marginados en beneficio de los países más ricos. Los países desarrollados tratan de demostrar que estas discusiones serían provechosas para todos, aunque no llegan a convencer a

\section{6}


los países menos pudientes. Europeos y norteamericanos se unen en esta tarea, pero queda por ver si los países en desarrollo se dejan apantallar por las atractivas proyecciones. No es mucho lo que se va a avanzar en este tema, que de momento queda en vía muerta.

A modo de postdata conviene agregar que algunos países como la India, Egipto, Nigeria y Paquistán se mostraron entre desconfiados y hostiles a la apertura de la presente cumbre. La India no dará su brazo a torcer hasta el último minuto. ("Agriculture et médicaments, les deux principales pommes de discorde", Le Monde, 09-11-01)

\section{Las manzanas de la discordia}

Fue necesario alargar de un día esta conferencia; de haber terminado el programado día 13, todos se hubieran ido como habían venido. Un primer logro fue el borrador sobre acceso a los medicamentos, discutido en la noche del domingo al lunes 12 de noviembre. El borrador, que debe ser sometido al plenario, prevé que el acuerdo sobre la propiedad intelectual "no puede impedir a los miembros aplicar medidas para proteger la salud pública" y les autoriza a "asegurar el acceso a los medicamentos genéricos". Esta versión ampliada se aplicaría al caso de 'pandemias' o epidemias generalizadas. El texto inicial dio lugar a diversas lecturas y aplicaciones: la convención multilateral autoriza a los Estados miembros de la OMC a recurrir a las licencias obligatorias y a las importaciones paralelas. Las primeras permiten a un país utilizar un medicamento patentado sin la autorización del país propietario de la licencia, en razón del interés general. Las segundas permiten comprar el medicamento, no en la casa matriz, sino en un tercer país a menor precio.

Como esta redacción había dado lugar a distorsiones y enfrentamientos ante la OMC, se desea llegar a un compromiso que permita a los países pobres proteger la salud pública sin dañar los derechos de las firmas productoras, desalentar la investigación médica y los beneficios de la investigación. Las discusiones se centran en la propuesta hecha por los Estados Unidos: "el derecho de los miembros a tomar medidas para proteger los derechos esenciales de la salud pública en el marco del acuerdo sobre la propiedad intelectual". ("A Doha, un accord de principe se dessine sur l'accés aux médicaments”, Le Monde, 13-11-01) Dos días después el plenario adopta un acuerdo que favorecería a los países en desarrollo, como la India y Brasil, al permitir fabricar medicamentos genéricos más baratos para la lucha contra pandemias como el SIDA. Pero no se trata de una victoria completa: "el acuerdo no sería válido para aquellos países que no puedan producir los medicamentos y que deban importarlos, porque el país exportador puede ser demandado ante la OMC por las naciones con industrias farmacéuticas por violar el derecho de propiedad intelectual a beneficio del país exportador”. Un paso adelante y un paso atrás en la aplicación de un acuerdo no muy preciso.

11 de septiembre, "Economío del Terror" y Cumbre de Qatar 
Las otras manzanas de la discordia han sido la agricultura, el textil y el medio ambiente. El fantasma de Seattle planea en Doha. La Unión Europea se vio presionada entre las cuerdas por los Estados Unidos y los países en desarrollo en razón de sus subvenciones a la agricultura. Los Estados Unidos trataron de presentar a los europeos como intransigentes proteccionistas porque así distraían la atención de su propia protección a los textiles, acero y a los medicamentos. Los europeos lucharon hasta el último momento para que se dialogara sobre una reducción y no una eliminación de las subvenciones agrícolas. Los miembros de la OMC se comprometieron a proseguir las negociaciones sobre "la reducción de todas las formas de subvenciones a la exportación, con miras a una progresiva reducción". Sin embargo, los europeos se resistían a aceptar el lérmino "progresiva reducción" como una "eliminación total", logrando que se agregara que el término "progresiva reducción no predetermina el resultado de las negociaciones". Es decir, que el resultado final será función de nuevas negociaciones. Algunos analistas opinan que "la cumbre de Doha ha significado el principio del fin de las ayudas europeas a la agricultura". Estas negociaciones dan la impresión de que aquí nadie nada por nada.

La India y otros países asiáticos y latinoamericanos lucharon hasta el último minuto para que Estados Unidos y Canadá aceptaran la reducción de sus aranceles a la importación de textiles, de un $28 \%$ a un $3 \%$. La firmeza de la India fue uno de los temas que obligó a prolongar de un día la conferencia, con la obligación de iniciar nuevas negociaciones. La India logró así ciertas victorias en el campo de los textiles y del acceso a lo medicamentos genéricos.

Si los europeos no quedaron tan malparados en el debate sobre subvenciones a las exportaciones agrícolas, no lograron que en el documento final de la OMC se introdujeran cláusulas obligatorias de respeto del medio ambiente y normas laborales o sociales. En este punto se plantearon tres posiciones. La Unión Europea pide que se reabran negociaciones sobre las relaciones fundamentales entre comercio y medio ambiente; un segundo grupo de países que no quieren discutir a profundidad este tema, y un tercer grupo que propone pasarlo a un comité de la OMC. Recordamos que estos debates ya se habían abierto en la cumbre de Seattle y, como dijera G. Soros, transcienden el campo propio de la OMC.

Otros temas quedan en suspenso, sometidos a nuevas negociaciones o en vía muerta hasta próximas reuniones. Por ejemplo, las normas a aplicar a las inversiones extranjeras y la competencia, así como las medidas antidumping de los Estados Unidos, tachadas de proteccionismo disimulado. Era imposible, en tres días, llegar a un acuerdo general sobre temas tan sensibles y espinosos, que dieron al traste con la reunión de Seattle. En Doha se trató de simplificar los documentos y dar la palabra a los delegados de países tan diferenciados en sus intereses y tan aferrados a sus demandas. En el último minuto se llegó a un Acuerdo Final. ("La agricultura, el textil y el medio ambiente amenazan el éxito 
de la cumbre de la OMC", El Pais, 13-11-01. "Agriculture et médicaments, les deux principales pommes de discorde", Le Monde, 09-11-01. "Accord pour lancer un nouveau cycle de negotiations commerciales", Le Monde, 15-11-01)

Terminada la cumbre los jefes de Estado y de Gobierno se felicitan por el éxito de la reunión, ya que su fracaso hubiera debilitado aún más la agobiada economía mundial. He aquí algunos testimonios. "La apertura de un nuevo ciclo de negociaciones es un signo de confianza en estos tiempos difíciles. En un mundo tan dividido se ha logrado algo muy importante". "Se ha logrado difuminar el fracaso de Seattle y reforzar el sistema multilateral, asegurar los mercados y a sus actores económicos, subrayando algunos temas prioritarios: el textil para los Estados Unidos, la agricultura para los europeos y los medicamentos y la apertura de mercados para los países en desarrollo". "Cuando la economía mundial sufre con la recesión en Japón, los Estados Unidos en declive y la Unión Europea no muy alentada, el acuerdo permite evitar un repliegue proteccionista, siempre posible en casos de crisis". "El mercado tiene una particular importancia para reforzar el comercio mundial y vigorizar la estabilidad de la economía, en un momento en que el futuro se hace cada vez más incierto"... ("Les capitales saluent l'acord conclu á l'issue de la conference ministerielle de l'OMC', Le Monde, 15-11-01)

La novedad de Qatar es que la OMC agrega al miembro 143 y amplía su mercado en mil trescientos millones de personas, con la ratificada integración de China. Su ingreso genera a la vez euforia y temores; su tasa de crecimiento es de $7 \%$ cuando la economía mundial crece sólo un $2 \%$. Su ingreso se ratifica luego de 15 años de difíciles negociaciones. Si de momento China se puede ver sometida a situaciones de desempleo en la agricultura y en el sector del automóvil, sus dirigentes esperan una gran expansión de la manufactura, textiles, juguetes y otros productos de consumo, así como una agricultura intensiva. Latinoamérica y otros países asiáticos enfrentarán la competencia de similares productos de la China, que, por añadidura, es gran productor de cultivos transgénicos. Mientras que las grandes empresas extranjeras se verán beneficiadas con la apertura que China hará en sus sectores más protegidos de telecomunicaciones, automóvil, banca y seguros. China ha aceptado a regañadientes el ingreso de Taiwan a la OMC, lo que no significa su reconocimiento como país independiente. ("China incorpora sus 1.300 millones de consumidores al comercio mundial”, El País, 11-11-01). Los negocios son los negocios: 1.300 millones de consumidores significa un atractivo mercado para las megaempresas occidentales. Que en China no se respeten los derechos humanos de la población no es tema de la OMC.

\section{La campaña del terror}

Decíamos que la 'economía del terror', según el G-20, son las fuentes de financiamiento que sostienen las actividades de los grupos terroristas, cuyo con-

II de septiembre, "Economía del Terror" y Cumbre de Qatar 
trol y exterminio se quiere llevar a cabo por la vía bancaria, judicial y militar. Merece la pena detenerse un momento en la vía judicial. Con fecha 26 de octubre, El País resume la siguiente determinación de la Unión Europea: "La UE dice que no habrá extradiciones a EE.UU. que impliquen la pena de muerte. La pena de muerte es un argumento suficiente para denegar una petición de extradición”. Diez días antes "George W. Bush había solicitado 'eliminar' algunas prácticas discriminatorias que se aplican contra Estados Unidos a la hora de examinar algunas demandas de extradición". Desde el pasado año los Quince habían dejado clara su posición: "nadie será trasladado, expulsado o extraditado a un Estado en el que existe un claro riesgo de que sea sometido a la pena de muerte, a torturas o tratos inhumanos, o a castigos denigratorios". El redactor de El País pone en letra negrilla este principio, "que la Unión mantiene como principio inalterable para los Quince: que ningún europeo entregará a Washington a presuntos terroristas, que allí puedan ser condenados a pena capital"... Se agrega, siempre en negrilla, que esto ha generado la polémica sobre la pesadilla que supondría para cualquier Gobierno europeo la posibilidad de que en su país acabe siendo detenido algún dirigente de Al Qaeda o incluso el propio Bin Laden. Esto significa que hay cierto distanciamiento entre la Unión Europea y los Estados Unidos en la campaña internacional contra el terrorismo. (El País, 26-10-01)

La razón de introducir este paréntesis es que al interior de los Estados Unidos se ha gestado una "campaña del terror": "Policías de Estados unidos se niegan a interrogar a inmigrantes de forma indiscriminada". El portaestandarte de la resistencia ha sido el jefe de la policía de Portland (Oregon), quien "fue el primero en negarse a cumplir una orden del Departamento de Justicia, según la cual unas 5.000 personas originarias del Oriente Próximo debían ser interrogadas, dentro de las investigaciones iniciadas el 11 de septiembre, pese a no estar relacionadas con ningún delito". Para el jefe de la policía esta orden vulnera las leyes contra la discriminación racial, amén de lesionar las libertades civiles de los Estados Unidos. Se le han unido otros jefes de policía quienes solicitan que, previamente, el FBI les indique qué crimen han cometido o puedan cometer. El fiscal general, John Ashcroft, pertenece al ala más derechista del partido republicano y, entre otras arbitrariedades, aprobó la segregación racial en las escuelas cuando fue fiscal y gobernador en Missouri. G. W. Bush se hizo acompañar de un fiel aliado que dio la orden de batir los barrios musulmanes e interrogar a unos 5.000 emigrantes procedentes de "países relacionados con el terrorismo".

Aunque la ley aprobada por el Congreso dice que se debe respetar "los derechos civiles de todos los americanos, incluyendo los árabes americanos y los musulmanes americanos", esta ley no se está cumpliendo. Cada vez más musulmanes repiten: "No quiero vivir en un Estado policial; la mayoría de nosotros abandonamos regímenes no democráticos en Oriente Próximo y ahora nos encontramos lo mismo aquí". Decenas de musulmanes están vendiendo sus negocios y sus propiedades y se van "por miedo" al acoso policial y al odio de sus 
vecinos. El miedo se acrecienta por el secreto que rodea a las detenciones, infligiendo los reglamentos sobre inmigración. Siete parlamentarios solicitaron la lista y paradero de los 1.182 detenidos, cifra revelada por el Departamento de Justicia, sin obtener respuesta, "para no invadir el derecho a la privacidad" de los detenidos y "porque sus identidades y paradero podría tener un efecto negativo en la investigación". (El País, 24-11-01) Una economía del terror que genera otra forma de economía del terror, o mejor dicho un terrorismo de Estado dentro y fuera del imperio.

"Las autoridades migratorias encuentran, en numerosos ciudadanos, entusiastas colaboradores a la hora de denunciar a los inmigrantes. El flujo de los mismos ha caído dramáticamente en la frontera sur, no tanto por temor al terrorismo islámico como al de los racistas y pseudopatriotas. Los siete millones que componen la comunidad musulmana de Estados Unidos están siendo víctimas de acoso, insultos y agravios continuos. Entre los extranjeros de etnias que corresponden al cliché que de los terroristas se ha formado la opinión pública, los ataques están siendo numerosos y ya han cobrado algunas víctimas. La sociedad norteamericana se mira dispuesta a aceptar cualquier restricción de los derechos y libertades fundamentales, con tal de superar la inseguridad actual". (R. Ribera: documento de próxima aparición)

\section{Mirarse en el espejo del mundo}

Con ocasión de la conferencia sobre Transición y Consolidación Democráticas, tenida en Madrid el 28 de octubre, Mikhail Gorbachov, padre de la Perestroika, dijo que "las víctimas de los atentados del 11 de septiembre en los Estados Unidos no habrán muerto en vano si el mundo aprovecha la ocasión para mirarse en el espejo y reflexionar sobre sí mismo y establecer un compromiso moral sin caer en el pánico". Parece que el pánico es un mal compañero del compromiso moral, porque no todo es moral en la persecución del terrorismo. Para comenzar, nos hace falta una definición de qué es terrorismo y quiénes son los terroristas. Este interrogante se planteó al más alto nivel. Las Naciones Unidas buscan integrar a todas las naciones en esta lucha, agregando que "las negociaciones sobre esta convención están estancadas desde hace más de un año, debido a que no hay un acuerdo sobre la definición de terrorismo. La Asamblea General de la ONU cerró ayer un debate sobre el terrorismo y dejó el asunto en manos de un grupo técnico, que deberá definir el término y proponer medidas concretas para su combate antes del 15 de noviembre". ( El País, 06-10-01)

He buscado, pero no he encontrado la definición de las Naciones Unidas. Tal vez el Grupo de los 20 la haya recibido .o, tal vez, sin una concreta definición han ratificado su compromiso de luchar contra el terrorismo y bloquear la "economía del terror", las fuentes de financiamiento de los grupos terroristas. Si estos 20 países se comprometen, cada uno en su país, a bloquear estas cuentas y 
a informar sobre las identidades de los terroristas y sus asociados, esto significa que trabajan, lista en mano, con los nombres y apellidos de los sentenciados. Aunque no pertenezcamos al Grupo de los 20 sería moralmente necesario que se hiciera pública la lista para evitar que cada Gobierno o cada fracción política agregue, por cuenta propia, nuevos nombres de posibles implicados. Es moralmente necesario que se diga quién hizo la lista, porque eso nos daría mayor grado de credibilidad si desean que todos nos integremos a la lucha antiterrorista. Si no se nos dan ciertos perfiles podemos repetir, con la mejor buena voluntad, frases indefinidas: "todos estamos unidos en contra del terrorismo y de los terroristas". Resulta que esta unión es algo incierta mientras no se definan los dos últimos términos de la frase. Estas preguntas no son una simple escapatoria.

En la cumbre de Ottawa un delegado del Banco Mundial lanzó una frase algo cabalística. A partir del 11 de septiembre "el mundo entero es diferente, más integrado y tiene que haber más unión entre países pobres y desarrollados, porque la alienación, la pobreza, la violencia, la ira son una amenaza para la paz y prosperidad en todo el mundo". La frase es cabalística porque daría a entender que la alienación, la pobreza...son, en sí mismas, un terrorismo pasivo, que amenaza la paz mundial. En el fondo esto significa que pueden estar cohabitando dos definiciones y dos experiencias de terrorismo, es decir, de hechos que causan terror, ira y violencia. Por eso interesa llegar a una definición más transparente del terrorismo. Los ministros de economía y jefes de los bancos centrales dan pie a estas reflexiones: "los países pobres serán los más perjudicados por el actual enfriamiento de la economía, agravada por los sucesos del 11 de septiembre. La pobreza en muchos países en desarrollo probablemente se agravará, porque estos acontecimientos han agudizado el enfriamiento previo de la economía mundial, que ya había llevado a menores exportaciones y caída de los precios de las materias primas".

La pregunta aquí es dónde comienza y dónde termina el terrorismo. Por supuesto que los ataques del 11 de septiembre, y hechos similares, son moralmente condenables y deleznables, y hay que unir esfuerzos para erradicarlos de nuestro mundo. Los ministros de economía dijeron: que la pobreza de los países pobres se agravará aún más, y que antes del 11 de septiembre el enfriamiento de la economía mundial ya había afectado las exportaciones y los precios de estos países. Ya existía la pobreza antes del año 2000; con el enfriamiento de la economía mundial en el 2001 se agrava esa pobreza, y con los actos del 11 de septiembre se profundiza la agravación. ¿Dónde comienza y dónde termina el terrorismo para el tercer mundo?. Por lo menos el presidente del Banco Mundial. James Wolfensohn, prometió algo más: "El Banco Mundial asume que debe ayudar más a los países pobres", agregando otra frase en blanco y negro: "Más ministros que nunca han hablado sobre el incremento de las ayudas al desarrollo, aunque no hay consenso". Esta falta de consenso la hemos observado en la conferencia de la OMC en Qatar, que termina el mismo día en que se inicia la reunión de Ottawa. 
Gorbachov había recomendado mirarse en el espejo del mundo. El problema es que cada cual utiliza su propio espejo. Espejismo y especulación tienen un origen común: el tamaño y la transparencia del propio espejo. Estas diferencias las pudimos observar en la conferencia de Naciones Unidas en Nueva York. G. W. Bush urge a la ONU a sumarse a la batalla contra el terrorismo, una amenaza planetaria; quien no se oponga a los terroristas pagará sus consecuencias. Pasó el tiempo de la misericordia y de las condolencias y ha llegado el momento de la acción. Distinto y más amplio es el espejo en que mira y se mira el Secretario General de la ONU. Las Naciones Unidas deben esforzarse por combatir la pobreza, el SIDA y otros conflictos, incluidos los cambios climáticos. Todos estos problemas pueden alimentar el terrorismo. Estamos tentados de concentrar todas nuestras energías en la lucha contra el terrorismo, pero esto sería conceder la victoria a los terroristas, porque los problemas a que nos habíamos enfrentado en la pasada cumbre de septiembre 2000 , no han cambiado, sino que se hacen más urgentes. Es necesario dar una esperanza real a millones de personas cercadas por la pobreza, los conflictos y las enfermedades.

Kofi Annan se suma a las voces de tantos manifestantes pacíficos, en distintas ciudades de Europa, que "reclaman el fin de los ataques aéreos contra Afganistán y piden una política de paz para contener el terrorismo". El lema es: "contra la guerra y a favor de la paz". Kofi Annan advirtió que "cuanto más se prolongue el conflicto mayor es la probabilidad de que se generen más tensiones, cuando lo importante es mantener un frente unido contra el terrorismo". Gorbachov había dicho. "Cuanto antes se llegue a una fase política será mejor para Afganistán y para nosotros... No se puede ganar una guerra contra Afganistán y destruir para ello una nación. Sería una locura. La operación tiene que tener objetivos muy concretos contra los terroristas y su infraestructura, y no debe provocar la muerte de personas inocentes igual que ellos. No debemos causar devastación y una inundación de refugiados. Este es el consenso de la comunidad internacional. Gorbachov recomienda integrar el papel de las Naciones Unidas y el derecho internacional en la acción contra el terrorismo.

El problema internacional que nos ha planteado la corta historia que une el 11 de septiembre y Afganistán es hasta dónde el fin justifica los medios. El problema es internacional porque en Serbia y Kosovo se habló de una "guerra humanitaria" y esa guerra no fue ciertamente humanitaria. El problema se plantea en el Medio Oriente, en la así llamada "tierra santa" de palestinos y judíos, donde unos piden una mediación más amplia y otros una más restringida; y ahora "otros" comienzan a hablar de un estado palestino. En 1998 se firman en Roma los estatutos de la Corte Penal Internacional, pero los Gobiemos que, por cuenta propia aplican la justicia penal, se niegan a ratificar este tratado. Todo esto significa que el problema del terrorismo es muy anterior al 11 de septiembre y que, así como hay que unir esfuerzos contra los temibles grupos terroristas, también hay que oponerse al terrorismo de Estado. Confiamos en que 
penalistas e institutos políticos y de derechos humanos nos sigan iluminando en este derrotero del derecho internacional. En la UCA se han impartido varias conferencias sobre el tema, que esperamos tengan la merecida publicación.

Volviendo a nuestro espejo del mundo y al mundo más integrado de que se habló en Ottawa, tenemos que decir que la cumbre de la OMC en Doha, Qatar, no nos ha dejado la impresión de un mundo muy integrado. Se dijo que la firma de un documento final era muy importante en un momento en que la economía mundial se halla en un proceso de severa recesión. Parece que se quiere integrar al mundo en las épocas de crisis, pero no tanto en los beneficios del auge y recuperación. El tercer mundo, como bloque, no fue actor del enfriamiento de las economías occidentales, cuyo epicentro fue la desbocada carrera especulativa de las inversiones en telecomunicaciones en los Estados Unidos. El tercer mundo, como bloque, fue un conmovido espectador de los hechos criminales del 11 de septiembre. Pero al tercer mundo le toca pagar los costos de lo que otros hacen. En El Salvador, como en otros países, ya estamos sintiendo y previendo los efectos recesivos del terrorismo en el mediano plazo, siendo ahora un ejercicio adivinatorio hacer proyecciones de crecimiento para el 2002. En Qatar no nos han brindado muchas oportunidades de llegar a ser partícipes de la anunciada recuperación.

Lo ratificado es que se seguirán las negociaciones sobre las subvenciones, los aranceles, los medicamentos, el textil y el acero, pero sin adelantar resultados. En la Conferencia Iberoamericana de Lima el tema mayor ha sido el terrorismo, venga de donde venga, y se deja para el 2002 el combate a la pobreza. Parece que el espejo del mundo se ha roto en varios pedazos y cada nación o cada grupo se mira en uno de los pedazos. Lo menos que podemos pedir es que no se nos imponga la cara del espejo con que mirar todos el mundo. Si queremos lograr la integración del mundo, la tarea pendiente es unir todas las partes del único espejo y llegar a un acuerdo sobre un terrorismo multifacético. 